\title{
Familial CD8 deficiency due to a mutation in the $\operatorname{CD8} \alpha$ gene
}

\author{
Oscar de la Calle-Martin, ${ }^{1}$ Manuel Hernandez, ${ }^{2}$ Jose Ordi, ${ }^{3}$ Natalia Casamitjana, ${ }^{1}$ \\ Juan I. Arostegui, ${ }^{1}$ Isabel Caragol, ${ }^{2}$ Monserrat Ferrando, ${ }^{2}$ Moises Labrador, ${ }^{3}$ \\ Jose L. Rodriguez-Sanchez, ${ }^{1}$ and Teresa Espanol${ }^{2}$
}

${ }^{1}$ Department of Immunology, Hospital de la Santa Creu i Sant Pau, Barcelona, Spain
${ }^{2}$ Immunology Unit, and
${ }^{3}$ Department of Internal Medicine, Hospitals Vall d'Hebron, Barcelona, Spain

Address correspondence to: Oscar de la Calle-Martin Department of Immunology, Hospital de la Santa Creu i Sant Pau, 08025 Barcelona, Spain. Phone: 34-93-2919017; E-mail: odlcalle@hsp.santpau.es.

Oscar de la Calle-Martin and Manuel Hernandez contributed equally to this work.

Received for publication August 8, 2000, and accepted in revised form May 21, 2001.

\begin{abstract}
CD8 glycoproteins play an important role in both the maturation and function of MHC class Irestricted $\mathrm{T}$ lymphocytes. A 25 -year-old man, from a consanguineous family, with recurrent bacterial infections and total absence of $\mathrm{CD8}^{+}$cells, was studied. Ab deficiencies and ZAP-70 and TAP defects were ruled out. A missense mutation (gly90 $\rightarrow$ ser) in both alleles of the immunoglobulin domain of the $C D 8 \alpha$ gene was shown to correlate with the absence of CD8 expression found in the patient and two sisters. Conversely, high percentages of CD4-CD8-TCR $\alpha \beta^{+} \mathrm{T}$ cells were found in the three siblings. A novel autosomal recessive immunologic defect characterized by absence of $\mathrm{CD}^{+}$ cells is described. These findings may help to further understanding of the role of CD8 molecules in human immune response.
\end{abstract}

J. Clin. Invest. 108:117-123 (2001). DOI:10.1172/JCI200110993.

\section{Introduction}

CD8 $\mathrm{T}$ cells recognize processed peptides associated with class I molecules of the MHC (1). Recognition of such peptide-MHC complexes by $\mathrm{T}$ cell receptors (TCRs) leads to cytotoxic T lymphocyte (CTL) activation and lysis of the cell presenting the ligand. This mechanism enables CTLs to recognize and eliminate infected cells (2), tumor cells (3), and allogeneic graft cells (4). CD8 molecules are expressed on the cell surface either as an $\alpha \alpha$ homodimer or as an $\alpha \beta$ heterodimer $(5,6)$, but surface expression of $\mathrm{CD} 8 \beta$ is dependent on expression of $\mathrm{CD} 8 \alpha$ because CD8 $\beta$ polypeptides are otherwise retained in the endoplasmic reticulum and degraded (7). Both chains $(\alpha$ and $\beta$ ) are composed of a single extracellular Ig superfamily (IgSF) V domain, a membrane proximal hinge region, a transmembrane domain, and a cytoplasmic tail (6). Comparison of CD8 $\alpha$ sequences from different animal species indicates that the basic structure of this molecule has been preserved during more than 400 million years of evolution (8). CD8 serves as a coreceptor for TCR recognition of MHC class I-associated peptides (5) and supports CTL activation by binding to the MHC, while making no direct contact with the peptide (9). The ability of CD8 to act as a TCR coreceptor lies in its capacity to interact with MHC class I and $\beta_{2-}$ microglobulin $\left(\beta_{2} \mathrm{~m}\right)$ (9-12). CD8 associates with $\beta_{2} \mathrm{~m}$ and the $\alpha 2$ and $\alpha 3$ domains of MHC class Ia molecules using its A/B $\beta$ strands and the complementary determining regions (CDRs) within the extracellular IgSF $\mathrm{V}$ domain. This association increases the adhesion/avidity of the $\mathrm{T}$ cell receptor with its class I target. In addition, CD8 associates with the $s c r$ tyrosine protein kinase $\mathrm{p} 56^{\text {lck }}$ through a conserved binding motif within its cytoplasmic tail (13-15). This latter event leads to the rapid activation of the cytotoxic T lymphocyte by internal signaling events. Expression of CD8 is characteristic of CTLs and is critical for their progression through the process of positive selection during differentiation in the thymus (16). An essential role for CD8 $\alpha$ during thymocyte development was demonstrated by gene targeting, as selection of cytotoxic $\mathrm{T}$ cells was greatly reduced in CD $8 \alpha^{-/-}$mice (17). Reduced thymic maturation but normal effector function of $\mathrm{CD}^{+} \mathrm{T}$ cells has been demonstrated in CD8 $\beta$ genetargeted mice $(18,19)$. Although CD8 knockout mice have been derived and their immunological characteristics published (17-22), no CD8 deficiency in humans has been described to date.

The case of a patient from a consanguineous family, with repeated respiratory bacterial infections and total absence of $\mathrm{CD}^{+}$cells, is presented. Ab deficiencies and ZAP-70 and TAP defects were ruled out, and molecular and genetic studies of CD8 were performed in the proband and his family. Family studies yielded two asymptomatic sisters with the same defect. Sequence analysis detected a homozygous missense mutation in the immunoglobulin domain of the CD $8 \alpha$ molecule in three out of ten family members studied. The findings reported in this new CD8 defect may help to further understanding of the role of CD8 molecules in human immune response. 


\section{Methods}

Patient and family studied. A 25-year-old male from a consanguineous Spanish Gypsy family was admitted with respiratory distress, weight loss, and general malaise of 1 month's duration. He had suffered repeated bouts of bronchitis with productive cough and otitis media from the age of five. Chest $x$-ray and computed tomography $(\mathrm{CT})$ revealed disseminated bronchiectases. Sputum culture was positive for Haemophilus influenzae. Functional respiratory tests revealed severe mixed ventilatory disturbance. Clinical status improved after intravenous antibiotic therapy. He has required further admissions because of respiratory reinfections. Although bacterial infections and bronchiectasis suggested an $\mathrm{Ab}$ deficiency, immunoglobulin levels and IgG subclasses were normal. Natural Ab's were in the low normal range and Ab's to different antigens tetanus, toxoplasma, Mycoplasma pneumoniae, cytomegalovirus (CMV), herpes zoster, herpes simplex, rubella - were present. Serologies to HIV and EpsteinBarr virus (EBV), Legionella pneumophila, Aspergillus, and Brucella were negative. Autoantibodies were negative. Complement levels and function and oxidative capacity of neutrophils were also normal. The XY karyotype was normal. Lymphocyte phenotyping detected total absence of $\mathrm{CD}^{+}$cells, both $\mathrm{CD}^{+}$and $\mathrm{CD}^{-}$. CD4 $\mathrm{T}$ cell, B cell, and natural killer $(\mathrm{NK})$ cell percentage and absolute numbers were normal. The patient is the fourth of nine siblings. None of the immediate family members had a relevant medical history. All the family members showed a normal immunophenotype, except two asymptomatic younger sisters who also presented total absence of $\mathrm{CD}^{+}$cells (Table 1 ). A differential diagnosis of immunodeficiency with low CD8 cells such as ZAP-70 (23) and TAP $(24,25)$ deficiencies was made: ZAP-70 protein expression and PBMC proliferative responses to different stimuli were normal in the patient. HLA class I molecule expression and NK cell cytotoxic activity against the class I-negative K562 cell line were also normal in the CD8-deficient patient.

The assay performed to study the CTL activity of the proband was a mixed lymphocyte reaction (MLR) (as described in ref. 26). Briefly, PBMCs from a bloodbank donor were used as stimulator/target cells. CTLs were derived from the patient (II-4) by incubating irradiated stimulator cells with responder, patient's, cells in three different concentrations of responders/stimulators in sensitization medium in 24-well microtiter plates for 7 days at $37^{\circ} \mathrm{C}$ with $5 \% \mathrm{CO}_{2}$, in an incubator. Separately, previously phytohemagglutinin-activated (PHA-activated) target cells were labeled with ${ }^{51} \mathrm{Cr}$ for 45 minutes in an incubator. ${ }^{51} \mathrm{Cr}$-labeled target cells were added to effector cells in triplicate at different effector/target ratios, in 96-well microtiter plates for 5 hours in an incubator. Control target cells from a different donor and control effector cells (nonsensitized) were also used in different curves at the same effector/target ratios. Two healthy controls were tested for CTL activity in the same plate.
Table 1

Immunological profile of CD8-deficient patient

Patient Reference range

Serum immunoglobulins $(\mathrm{mg} / \mathrm{dl})$

$\lg G$

$\lg A$

$\lg M$

$\lg G 2$

$\begin{array}{lc}1,920 & 850-1,600 \\ 474 & 75-350 \\ 201 & 52-235 \\ 278 & 112-408\end{array}$

Lymphocyte subpopulations (cells $/ \mathrm{mm}^{3}$ )

CD3

CD4

CD8

TCR $\alpha \beta$

TCR $\gamma \delta$

CD19

CD16 + CD56

$1,080 \quad 690-2,540$

$750 \quad 410-1,590$

$0 \quad 190-1,140$

$990 \quad 656-2,413$

$90 \quad 20-157$

$105 \quad 90-660$

$195 \quad 90-590$

Lymphocyte proliferation (cpm)

Medium control

$\mathrm{PHA}$

958

66,552

43,229

Anti-CD3

PMA + ionomycin

SEA

SEB

Tetanus toxoid

80,497

24,991

32,909

41,414

Allogenic cells

8,500

$500-1,466$

43,238-78,996

$28,234-50,344$

$69,852-85,323$

$19,588-32,563$

$21,356-37,581$

$21,321-47,254$

4,589-20,147

NK cell function (\% lysis of K562 cells)

Effector-to-target ratio

$\begin{array}{lcc}1: 50 & 54 & 28-57 \\ 1: 25 & 27 & 23-45 \\ 1: 12.5 & 21 & 10-34 \\ 1: 6.25 & 12 & 6-28\end{array}$

SEA, Staphylococcus enterotoxin A; SEB, Staphylococcus enterotoxin B.

Flow cytometric analysis. Whole blood samples from the patient, the parents, and seven siblings were stained with an extensive panel of anti-CD $8 \alpha \mathrm{mAb}$ 's (Becton Dickinson, San Jose, California, USA; Coulter-Immunotech, Miami, Florida, USA; Serotec Ltd., Oxford, United Kingdom; OncoScience, Frankford, Germany; Santa Cruz Biotechnology Inc., Santa Cruz, California, USA; and Ortho Clinical Diagnostic Systems, Tokyo, Japan), anti-CD8 $\beta$ (5H7; CoulterImmunotech), and anti-TCR V $\beta$ (anti-V $\beta 5$, anti-V $\beta 7.1$, anti-V $\beta 12$, anti-V $\beta 13$, and anti-V $\beta 17$ from Endogen Inc., Woburn, Massachusetts, USA; anti-V $\beta 3.1$, anti$V \beta 6.7$, and anti-V $\beta 8$ from Innogenetics, Inc., Gante, Belgium). Indirect immunofluorescence with antiCD8 $\alpha$ (109-2D4, 143-44, and 138-17 donated by R. Vilella, Department of Immunology, Hospital Clinic, Barcelona, Spain) and anti-CD8 $\beta$ (5F2; CoulterImmunotech) was also performed. The same analysis was applied to transfected cells. Fluorescence-stained cells were analyzed by a FACSCalibur (Becton Dickinson Immunocytometry Systems, San Jose, California, USA) or an EPICS XL (Coulter Electronics Inc., Miami, Florida, USA).

Western blot analysis. PBMCs were lysed in $1 \%$ Nonidet P-40 lysis buffer. Proteins from the lysates were resolved in reducing conditions by SDS-PAGE and transferred onto nitrocellulose membranes (Bio-Rad Laboratories Inc., Hercules, California, USA) using a semidry blotter 
(Bio-Rad Laboratories Inc.). Incubation was made with a polyclonal antiserum anti-ZAP-70 (Santa Cruz Biotechnology Inc.), mAb anti-CD8 $\beta$ (2ST8-5H7, kindly donated by E.L. Reinherz, Dana-Faber Cancer Institute, Boston, Massachusetts, USA; and 5F2 from Coulter-Immunotech), and anti- $\beta$-actin (Sigma Chemical Co., St. Louis, Missouri, USA). Antigen-Ab complexes were visualized using the enhanced chemiluminescence detection system (ECL; Amersham International, Amersham, United Kingdom).

Amplification of CD8 $\alpha$ and $\beta$ mRNA. Total RNA was extracted from peripheral blood lymphocytes by standard methods (Ultraspec RNA; Biotech Laboratories, St. Louis, Misouri, USA) and then subjected to RT-PCR amplification. CD $8 \alpha\left(5^{\prime}\right.$-GTC ATG GCC TTA CCA GTG AC- $3^{\prime}$ and $5^{\prime}$-GCA CGA AGT GGC TGA AGT AC- $\left.3^{\prime}\right)$ and CD $8 \beta$ ( $\alpha 5^{\prime}$-CAG CTG ACA GTT CTC CAT GG-3' and $5^{\prime}$-CGG CAC ACT CTC TTC TTG AG- $3^{\prime}$ ) primers were annealed at $55^{\circ} \mathrm{C}$, and $25-30$ cycles of amplification were performed. Levels of $\beta$-actin were used as RT-PCR control. The PCR products were visualized on $1.5 \%$ agarose gels.

Sequence analysis. One microgram of total RNA was reverse-transcribed into first-strand cDNA using Superscript II RT (Life Technologies Inc., Pisley, United Kingdom). One-tenth of the cDNA was amplified by PCR with the Expand High-Fidelity PCR system (Boehringer Mannheim Biochemicals Inc., Mannheim, Germany) using the following primers: forward 5'-CGA AAA GGA GGG TGA CTC-3'; reverse 5'-CGC CCC CAC TAA AAT AAT- $3^{\prime}$ (27). The PCR products were visualized on $1.5 \%$ agarose gels and cloned into PCR2.1 TOPO vector (Invitrogen Corp., Carlsbad, California, USA). Sequencing was performed with the ALFexpress AutoCycle Sequencing Kit (Amersham Pharmacia Biotech, Piscataway, New Jersey, USA) and an ALFexpress sequencer (Amersham Pharmacia Biotech). For analysis of the point mutation in exon 2 (immunoglobulin domain), genomic DNA was prepared from fresh mononuclear blood cells from the patient, siblings, and their parents. The PCR products were amplified with the following primers: forward 5 '-GTC ATG GCC TTA CCA GTG AC-3'; reverse 5'-GTT GAG GTG AAC CCC AAG CC-3' (intron 2) (28). The 550-bp product was purified and directly sequenced from both strands with the Applied Biosystems PRISM dye terminator cycle-sequencing kit (Perkin Elmer Applied Biosystems, Foster City, California, USA) and an ABI DNA sequencer (Perkin-Elmer).

Mutagenesis and transfection studies. Wild-type and mutated CD8 were subcloned into the XbaI/SacI sites of pCDL-SR 2296 vector (29). Chimeric CD8 molecules (CD8 MUT/WT and WT/MUT) were constructed and subcloned into the PCDL-SR $\alpha 296$ vector. CD8 singlepoint mutants were generated by site-directed mutagenesis of the wild-type (WT CD8 > CD8 ${ }^{\text {ser90 }}$ or CD8 $8^{\text {arg90 }}$ ) and mutated CD8 (mutant CD8 > CD8 ${ }^{\text {gly90 }}$ ), using the QuikChange Site-Directed Mutagenesis Kit (Stratagene, La Jolla, California, USA).

\section{Results}

Total absence of CD8 and high percentage of $C D 4^{-} C D 8^{-} T C R \alpha \beta^{+}$ $T$ cells. Flow cytometric analysis in a patient with repeated sino-pulmonary infections showed a complete lack of $\mathrm{CD}^{+}$cells in peripheral blood (Figure 1a and Table 1). Since the parents were consanguineous, the members of his family were analyzed. Two sisters were also found to have a complete absence of CD8 cells. Parents (father: I-1; mother: I-2), CD8-deficient siblings (patient: II-4; sisters: II-5, II-7), and other brothers and sisters (II-1, II-2, II-3, II-8, II-9) were studied further. Membrane and intracellular (data not shown) expression of CD8 $\alpha$ molecules in $\mathrm{T}$ and NK lymphocytes and serum SCD8 concentration were below detectable limits in the three affected siblings. Mean fluorescence intensity of CD $8 \alpha$ expression on cell surface and SCD 8 were decreased in the parents and two brothers (II-2 and II-8), but normal in the remaining siblings. Weak expression of CD8 $\beta$ was detected by Western blot analysis in PBMCs of the patient (Figure 1b) and two CD8-deficient sisters; however, CD8 $\beta$ membrane expression was absent (data not shown). Messenger RNAs for CD8 $\alpha$ and $\beta$ were detected by RT-PCR at similar levels in the CD8-negative individuals, their relatives, and normal controls (Figure 1c). The three CD8-deficient siblings showed a higher percentage of CD4- ${ }^{-} 8^{-} \mathrm{T}$ cells than normal donors. This increase was due to the rise in CD4-CD8-TCR $\alpha \beta^{+}$T cells $(\alpha / \beta$ DN $\mathrm{T}$ cells) (II-4 $=16 \%$, II-5 $=10 \%$, and II-7 = 4\%; reference range $=0.1-2 \%$ ) with a wide $V \beta$ repertoire. The percentage of CD4- $4^{-} 8^{-} \mathrm{TCR} \delta^{+} \mathrm{T}$ cells was normal (II-4 $=6 \%$, II- $5=4 \%$, and II-7 $=3 \%$; reference range $=1-8 \%$. The

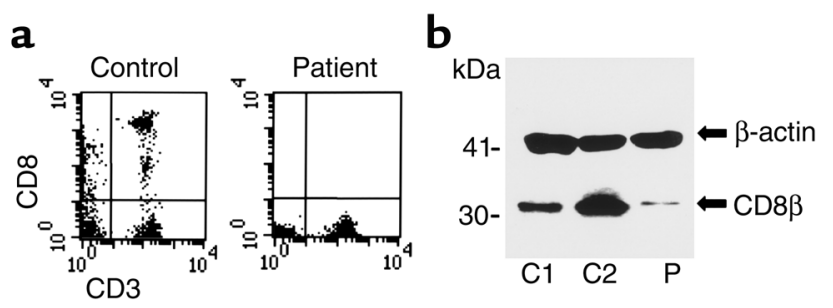

C

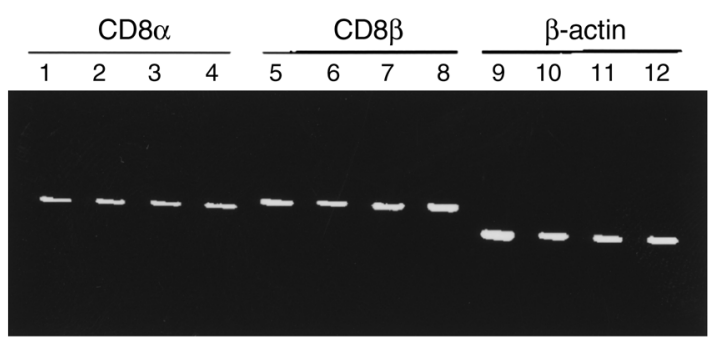

\section{Figure 1}

CD8 expression analysis. (a) Expression of CD8 on T lymphocytes and $\mathrm{CD}^{-}$- cells in the CD8-deficient patient and a healthy donor. (b) CD8 $\beta$ expression studied by Western blot analysis in two controls ( $C 1$ is a primary immunodeficient patient with low CD8 T cells and C2 is a healthy adult) and in the CD8-deficient patient. Weak intracellular expression of this molecule was detected in the patient; $\beta$-actin was the same as in controls. (c) Messenger RNAs for CD8 $\alpha$ and $\beta$ were detected by RT-PCR at similar levels in the CD8-negative individuals, their relatives, and normal control. 
Wild-type

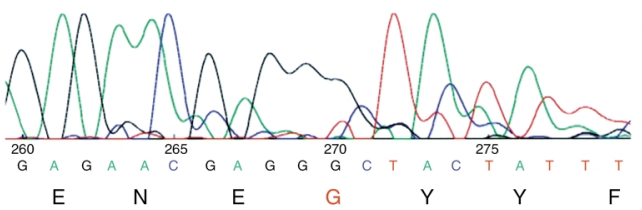

Mutant

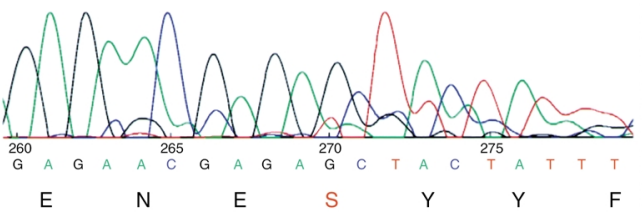

Figure 2

Mutation in the messenger RNA-coding region of the $\operatorname{CD} 8 \alpha$ gene. Sequence of the CD8 $\alpha$ cDNA reveals a nucleotide substitution $(\mathrm{G} \rightarrow \mathrm{A})$ at position 331 (numbered from the ATG sequence initiating the coding region), leading to the replacement of a glycine by a serine at position 90 .

predominant immunophenotype found in these $\alpha / \beta$ DN T cells was $\mathrm{CD} 3^{\text {hi }} \mathrm{CD}^{+} \mathrm{CD}^{+}{ }^{+} \mathrm{CD}_{4} \mathrm{RA}^{+} \mathrm{CD} 57^{+}$ $\mathrm{CD}_{11} \mathrm{~b}^{+} \mathrm{CD} 28^{-}$and IFN- $\gamma^{+}$IL-2- IL-4- (with in vitro stimulation) (data not shown), suggestive of effector cytotoxic cells (30).

To demonstrate the cytotoxic activity of these cells an allogeneic CTL test was performed with the method described, but unfortunately the results were not conclusive, although tests were repeated. No further samples are available at the present time. NK cytotoxicity was shown to be normal despite the absence of CD8 in these cells.
Autosomal recessive familial CD8 deficiency. Genetic studies of CD $8 \alpha$ molecule were conducted in view of the above-mentioned results. Primers were chosen to generate a product covering the entire coding region and the $5^{\prime}$ and $3^{\prime}$ untranslated regions (UTRs) for CD $8 \alpha$ by RT-PCR. PCR products were subcloned in plasmid vectors and sequenced. Sequences from recombinant clones derived from different PCR products showed a nucleotide substitution in the three siblings, but not in the controls. The $\mathrm{G} \rightarrow \mathrm{A}$ mutation found produces a change from glycine to serine residue at position 90 (Figure 2). The glycine at position 90 (gly90) is located in the immunoglobulin domain of the CD8 $\alpha$ chain and is conserved in all reported species, and also in the corresponding region of the closely related molecules $\mathrm{CD} 8 \beta$ and $\mathrm{CD} 7(8,31)$.

Intrafamilial segregation of the mutant allele was analysed to confirm its role in the CD8 deficiency. Genomic analysis of the patient's and his relatives' DNA, including the two parents, was performed by direct sequencing of genomic PCR products to establish the inheritance of the mutant allele. The three CD8deficient siblings were indeed homozygous for the mutated allele $\left(\mathrm{CD} 8^{\mathrm{ser} 90}\right)$. The parents and two brothers found to have lower CD8 expression were heterozygous carriers, whereas three sisters with normal CD8 levels were homozygous for the wild-type alleles. The levels of CD8 as detected by flow cytometry (membrane-bound CD8) and ELISA (soluble CD8) correlated strictly with the genotype of the family members (Figure 3).

Highly conserved gly90 is responsible for $\mathrm{CD} 8$ expression. The presence of the single amino acid substitution that clearly segregates in a classic Mendelian fashion with
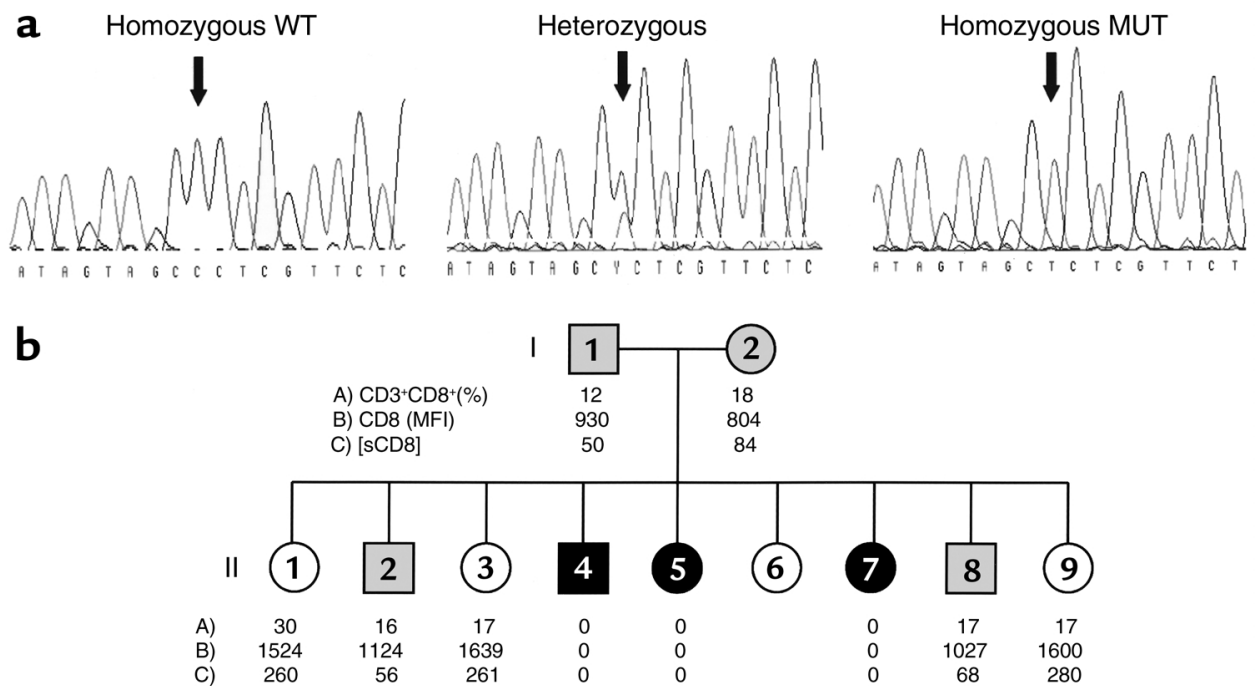

\section{Figure 3}

Segregation of the mutation in the CD8 $\alpha$ gene. (a) Sequence of the genomic DNA for the CD8 $\alpha$ gene of the patient (II-4), his father (I-2), and an unaffected sibling (II-1). This sequence corresponds to the complementary strand around position 331 of the CD8 $\alpha$ gene and was performed with the PCR products as templates. (b) Pedigree, including genotype and phenotype data of CD8. Square symbols denote male and circles female family members; filled symbols denote homozygous mutant allele; shaded symbols represent heterozygous carriers of the mutant $C D 8 \alpha$ allele; open symbols represent homozygous wild-type alleles. A) percentage of $C D 3^{+} C D 8^{+} T$ cells; $B$ ) fluorescence intensity of $\mathrm{CD} 8 \alpha$ expression; $\mathrm{C})$ soluble $\mathrm{CD} 8$ concentration in serum $(\mathrm{U} / \mathrm{ml})$. Family member II- 6 was not tested. 

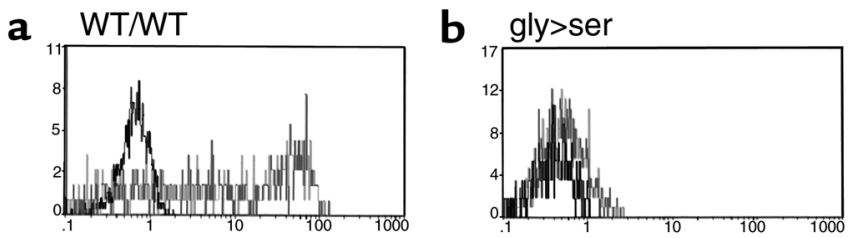

MUT/MUT

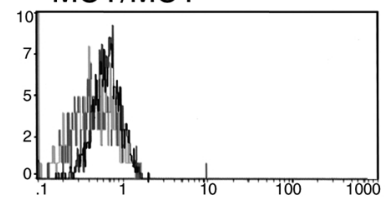

WT/MUT

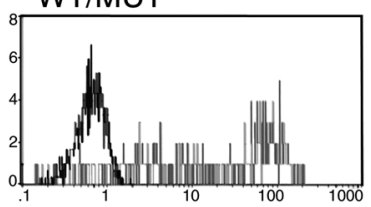

MUT/WT

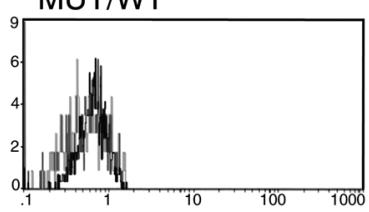

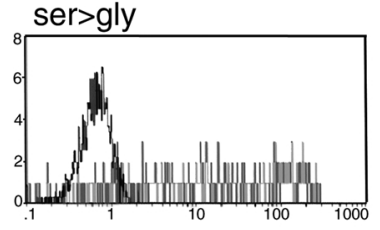

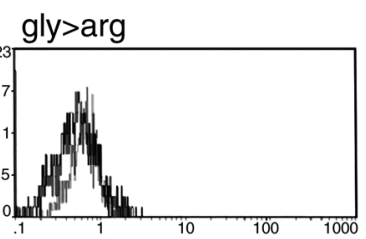

wild-type CD8 used for the expression experiments was engineered to produce two single mutants $\left(\mathrm{CD}^{\mathrm{ser} 90}\right.$ and $\mathrm{CD} 8^{\text {arg90}}$ ), whereas the mutant $\mathrm{CD} 8$ prepared from the patient reverted to CD8gly90. The presence of serine or another amino acid (arginine) prevents CD8 expression (Figure 4b), thereby suggesting that the presence of the evolutionary conserved glycine at this position may be important for appropriate folding of the protein. Moreover, the single reversion of the serine to a glycine in the mutant gene restored full CD8 expression, hence showing that this unique mutation is sufficient to avoid a proper CD8 expression. Cotransfection experiments with $C D 8 \beta$ also showed complete absence of $C D 8 \alpha \beta$ heterodimers (data not shown), as already observed in the affected individuals. Taken together, these data demonstrate that substitution of gly 90 in the immunoglobulin domain is responsible for the complete absence of CD8 expression observed in the affected members of this family and may be related to the clinical status of the patient.

\section{Discussion}

An autosomal recessive familial CD8 deficiency due to a single mutation in the $\mathrm{CD} 8 \alpha$ gene is described. $\mathrm{CD} 8^{+}$cells were shown to be absent in a patient with repeated bacterial infections in whom other known immunodeficiencies were ruled out. Familial studies showed the same defect in two sisters from the same consanguineous parents.

$\mathrm{CD} 8 \alpha$ chain was found to be completely absent in three members of this family, whereas scarce expression of $C D 8 \beta$ chain was detected in their cytoplasm. CD8 glycoproteins are expressed predominantly on MHC class I-restricted T cells as a disulfide-linked $\alpha \beta$-heterodimer, but can also be expressed as an $\alpha \alpha-$ homodimer in NK cells and intraepithelial T cells (6, $32,33)$. In the absence of $C D 8 \alpha, C D 8 \beta$ is retained and destroyed within the cell (7), whereas $C D 8 \alpha$ can be expressed at the cell surface without CD8 $\beta$ as CD8 $\alpha \alpha$ homodimers. These data, together with normal mRNA expression for $\operatorname{CD} 8 \alpha$ and $\beta$, led us to postulate that the defect could more probably involve the CD8 $\alpha$ gene. Therefore, genetic analysis was performed, and a missense mutation (gly90 $\rightarrow$ ser) in the CD8 $\alpha$ gene was found to be present in both alleles of the CD8-deficient individuals. In all family members, the genotype correlated strictly with the CD8 phenotype observed. No CD8 molecules could be detected in the cells or sera of the homozygous individuals with any of the anti-CD8 Ab's tested, whereas heterozygous subjects showed impaired CD8 expression both on the cell surface of $\mathrm{CD}^{+}$lymphocytes and in serum.

A serine in the mutant allele replaced the glycine residue, which is well preserved in the $\mathrm{F}$ strand of the immunoglobulin domain of all known $\mathrm{CD} 8 \alpha$ molecules from fish to humans (over 400 million years) (8). This particular glycine is also conserved in the closely related molecules CD8 $\beta$ and CD7 (31). The importance 
of this particular mutation in CD8 was also established by our in vitro experiments. Mutant CD8 constructs that lack gly90 cannot be detected on the surface or in cytoplasm of transiently transfected COS-7 cells. The relevance of gly 90 was further demonstrated by the transfection of chimeric CD8 molecules and by sitedirected mutagenesis-generated molecules. Taken together, these experiments demonstrated the need for gly90 in the immunoglobulin domain of $\mathrm{CD} 8 \alpha$, since its substitution by another amino acid, arginine, resulted in an identical lack of detection. Furthermore, these results showed that substitution of the glycine residue was sufficient to avoid CD8 expression, thereby ruling out the possibility that a mutation in noncoding sequences, that is, regulatory sequences, could be responsible for the lack of CD8 found in this family. Although the glycoprotein CD8 plays an important role in the maturation and function of MHC class I-restricted $\mathrm{T}$ lymphocytes, as clearly shown by either $\mathrm{CD} 8 \alpha$ or $\mathrm{CD} 8 \beta$ knockouts (17-19), its presence does not appear to be essential for either CD8 lineage commitment or peripheral cytolytic function. It has been reported that TCR transgenic thymocytes from CD $8 \alpha$-deficient mice were able to restore positive selection of CD8 lineage cells (as shown by CD8 $\beta$ expression) in the absence of CD8, thereby compensating for the lack of CD8 expression by increasing the affinity of TCR for the positively selecting ligand $(7,34,35)$. Recent reports addressing the mechanism of $\mathrm{CD} 4 / \mathrm{CD} 8$ lineage commitment are consistent with a model in which recognition of class I or class II MHC directs thymocytes to the appropriate lineage (instructive model) (36-38). The presence or absence of coreceptor-related signals (CD4, $\mathrm{CD} 8$, or $\left.\mathrm{p} 56^{\mathrm{lck}}\right)$ can further modulate the selection process, but lineage commitment can take place in the absence of the appropriate coreceptor. Polyclonal $\alpha / \beta$ $\mathrm{DN} T$ cells found in the CD8-deficient individuals were most probably committed to being CD8 cytotoxic T cells, because several findings strongly suggest: (a) a high percentage of $\alpha / \beta$ DN T cells in our patient were CD11 $\mathrm{b}^{+}$ $\mathrm{CD}^{2} 7^{+} \mathrm{CD} 45 \mathrm{RA}^{+} \mathrm{CD} 28^{-} \mathrm{IFN}^{+}$IL-2- IL-4-, a phenotype associated with effector $\mathrm{CD}^{+}$cytotoxic $\mathrm{T}$ lymphocytes (30); (b) the absence of CD4 expression in a substantial number of peripheral T cells $(\alpha / \beta$ DN T cells) in these CD8-deficient individuals suggests a specific CD4 antigen downregulation event; and (c) transcripts for $\mathrm{CD} 8 \alpha$ and CD8 $\beta$ were detected at similar levels in the CD8-negative individuals, as in their heterozygous relatives or normal controls. These findings indicate that $\mathrm{CD} 8$ transcription can continue without direct binding of CD8 to MHC I molecules during thymic selection.

The clinical manifestations present in the affected member of this family, as in the murine counterpart (CD8 $\alpha$ mice) (20-22), are not severe. This syndrome, as TAP1 and TAP2 deficiencies, is compatible with life, but seems to be less aggressive than the HLA class I deficiencies. Probably, the absence of CD8 is more critical for the development of the cytotoxic $\mathrm{T}$ cell repertoire than for the effector function in the periphery.
We believe that the absence of classic CTL CD8 ${ }^{+}$may be partially compensated for by the cytolytic function of $\alpha / \beta$ DN T cells and the NK cell activity. However, as the impact of the CD8 absence in CTL function could not be properly addressed in this patient, further studies on CD8 cell function, such as allogeneic cytotoxicity or cytotoxicity to recall antigens and DN T cell repertoire, are required before the significance of this CD8 defect can be better interpreted.

The high Ab titers to many viral infections (CMV, herpes zoster, herpes simplex, rubella) in the patient would seem to demonstrate that he has been in contact with these viruses and immunocompetent enough to overcome these infections. Although analysis of the recent infections in the proband showed only those of bacterial nature, viral infections suffered at an early age might have been responsible for the alveolar lesions that have later become over-infected and have produced bronchiectases, as reported in TAP-deficient patients (24-25). The diagnosis of pelvic inflammatory disease (PID) in adults is more frequently reported (39-41), and it remains to be seen whether the CD8negative sisters will develop symptoms in the future. Examples of poor correlation between genotype and clinical symptoms in other PID patients are described in the literature $(24,42-44)$, and factors such as polymorphisms in other host defense molecules associated with monogenic disorders (45) could also be involved in phenotypic differences in PID with the same genetic defect.

The prevalence of this particular CD8 defect with such a dramatic effect on lymphocyte phenotype should be extremely low, since CD8 expression has been widely determined without any similar case being reported. Nevertheless, mutations in CD8 that affect MHC I binding or signal transduction capabilities without substantial impairment of CD8 expression may be more frequent than expected and should be investigated in patients with repeated infections that resemble $\mathrm{Ab}$ deficiencies.

A novel immunological defect is described and a point mutation in the $\mathrm{CD} 8 \alpha$ gene is demonstrated to be responsible for this autosomal recessive familial CD8 deficiency. We believe that many lessons on the role of the CD8 molecule in the maturation and function of MHC class I-restricted T lymphocytes can be learned from the study of this natural human model of immunologic defect.

\section{Acknowledgments}

We are indebted to J.A. Garcia-Sanz (Centro Nacional de Biotecnologia-Consejo Superior de Investigaciones Cientificas [CNB-CSIC], Madrid) for the critical review of the manuscript and to C. O'Hara for the assistance with the English version of the paper. This work is supported in part by a grant (ACES98-46/5) from the Direcció General de Recerca (Generalitat de Catalunya) and by a grant (98/0409) from the Fondo de Investigación Sanitaria (Ministerio de Sanidad y Consumo). 
Note added in proof: The accession number for the mutant CD8 alpha allele described here is AY039664.

1. Townsend, A., and Bodmer, H. 1989. Antigen recognition by class Irestricted T lymphocytes. Annu. Rev. Immunol. 7:601-624.

2. Zinkernagel, R.M., and Doherty, P.C. 1979. MHC-restricted cytotoxic T cells: studies on the biological role of polymorphic major transplantation antigens determining $\mathrm{T}$ cell restriction-specificity function and responsiveness. Adv. Immunol. 27:51-77.

3. Tanaka, K., Yoshioka, T., Bieberich, C., and Jay, G. 1998. Role of the major histocompatibility complex class I antigens in tumor growth and metastasis. Annu. Rev. Immunol. 6:359-380.

4. Mason, D.W., and Morris, P.J. 1986. Effector mechanisms in allograft rejection. Annu. Rev. Immunol. 4:119-145.

5. Janeway, C.A. 1992. The T cell receptor as a multicomponent signalling machine: CD4/CD8 coreceptors and CD45 in T cell activation. Annu. Rev. Immunol. 10:645-674.

6. Zamoyska, R. 1994. The CD8 coreceptor revisited: one chain good, two chains better. Immunity. 1:243-246

7. Goldrath, A.W., Hogquist, K.A., and Bevan, M.J. 1997. CD8 lineage commitment in the absence of CD8. Immunity. 6:633-642.

8. Hansen, J.D., and Strassburger, P. 2000. Description of an ectodermic TCR coreceptor, $\mathrm{CD} 8 \alpha$, in rainbow trout. J. Immunol. 164:3132-3139.

9. Gao, G.F., et al. 1997. Crystal structure of the complex between human CD8 $\alpha \alpha$ and HLA-A2. Nature. 387:630-634.

10. Salter, R.D., et al. 1990. A binding site for the T-cell receptor CD8 on the alpha 3 domain of HLA-A2. Nature. 345:41-46.

11. Sanders, S.K., Fox, R.O., and Kavathas, P. 1991. Mutations in CD8 that affect interactions with HLA class I and monoclonal anti-CD8 antibodies. J. Exp. Med. 174:371-379.

12. Sun, J., Leahy, D.J., and Kavathas, P. 1995. Interaction between CD8 and major histocompatibility complex (MHC) class I mediated by multiple contact surfaces that include the $\alpha 2$ and $\alpha 3$ domains of MHC class I. J. Exp. Med. 182:1275-1280.

13. Turner, J.M., et al. 1990. Interaction of the unique $\mathrm{N}$-terminal region of tyrosine kinase p56lck with cytoplasmic domains of CD4 and CD8 is mediated by cystein motifs. Cell. 60:755-765.

14. Chapupny, N.J., Ledbetter, J.A., and Kavathas, P. 1998. Association of CD8 with p56lck is required for early $\mathrm{T}$ cell signalling events. EMBO J. 10:1201-1207.

15. Veillette, A., Bookman, M.A., Horak, E.M., and Bolen, J.B. 1988. The CD4 and CD8 $\mathrm{T}$ cell surface antigens are associated with the internal membrane tyrosine-protein kinase p56lck. Cell. 55:301-308.

16. Zamoyska, R. 1998. CD4 and CD8: modulators of T-cell receptor recognition of antigen and of immune responses? Curr. Opin. Immunol. 10:82-87.

17. Fung-Leung, W.P., et al. 1991. CD8 is needed for development of cytotoxic T cells but not helper T cells. Cell. 65:443-449.

18. Nakayama, K.I., et al. 1994. Requirement for CD8 $\beta$ chain in positive selection of CD8-lineage T cells. Science. 263:1131-1133.

19. Fung-Leung, W.P., et al. 1993. The lack of CD $8 \alpha$ cytoplasmic domain resulted in a dramatic decrease in efficiency in thymic maturation but only a moderate reduction in cytotoxic function of CD8+ T lymphocytes. Eur. J. Immunol. 23:2834-2840.

20. Fung-Leung, W.P., Kündig, T.M., Zinkernagel, R.M., and Mak, T.W. 1991. Immune response against lymphocytic choriomeningitis virus infection in mice without CD8 expression. J. Exp. Med. 174:1425-1429.

21. Huber, M., Timms, E., Mak, T.W., Rollinghoff, M., and Lohoff, M. 1998. Effective and long-lasting immunity against the parasite Leishmania major in CD8-deficient mice. Infect. Immun. 66:3968-3970.

22. Xing, Z., Wang, J., Croitoru, K., and Wakeham, J. 1998. Protection by CD4 or CD8 T cells against pulmonary Mycobacterium bovis bacillus Calmette-Guerin infection. Infect. Immun. 66:5537-5542.

23. Chan, A.C., et al. 1994. ZAP-70 deficiency in an autosomal recessive form of severe combined immunodeficiency. Science. 264:1599-1601.

24. De la Salle, H., et al. 1994. Homozygous human TAP peptide transporter mutation in HLA class I deficiency. Science. 265:237-241.

25. De la Salle, H., et al. 1999. HLA class I deficiencies due to mutations in subunit 1 of the peptide transporter TAP1. J. Clin. Invest. 103:R9-R13.

26. Wunderlich, J., Shearer, G., and Livingstone, A. 1997. Induction and measurement of cytotoxic T lymphocyte activity. In Current protocols in immunology. Volume 1. J.E. Coligan, D.H. Konisbeck, E.M. Sheach, and W. Strober, editors. John Wiley and Sons, Inc. USA. 3.11.1-3.11.20.

27. Littman, D.R., Thomas, Y., Maddon, P.J., Chess, L., and Axel, R. 1985. The isolation and sequence of the gene encoding T8: a molecule defining functional classes of T lymphocytes. Cell. 40:237-246.

28. Nakayama, K., Tokito, S., Okumura, K., and Nakauchi, H. 1989. Structure and expression of the gene encoding CD8 $\alpha$ chain (Leu-2/T8). Immunogenetics. 30:393-397.

29. Takebe, Y., et al. 1988. Sr $\alpha$ promoter: an efficient and versatile mammalian cDNA expression system composed of the simian virus 40 early promoter and the R-U5 segment of human T-cell leukemia virus type 1 long terminal repeat. Mol. Cell. Biol. 8:466-472.

30. Hamann, D., Roos, M.Th.L., and Lier, R.A.W. 1999. Faces and phases of human CD8+ T-cell development. Immunol. Today. 20:177-179.

31. Barclay, A.N., Brown, M.H., Law, S.K.A., McKnight, A., and Tomlinson, M. 1997. The leucocyte antigen factsbook. 2nd edition. Academic Press Inc. London, United Kingdom. 149-151.

32. Moebius, U., Kober, G., Griscelli, A.L., Hercend, T., and Meuer, S.C. 1991. Expression of different CD8 isoforms on distinct human lymphocyte subpopulations. Eur. J. Immunol. 21:1793-1800.

33. Terry, L.A., DiSanto, J.P., Small, T.N., and Flomenberg, N. 1990. Differential expression and regulation of the human $\operatorname{CD} 8 \alpha$ and $C D 8 \beta$ chains. Tissue Antigens. 35:82-91.

34. Sebzda, E., Choi, M., Fung-Leung, W.P., Mak, T.W., and Ohashi, P.S. 1997. Peptide-induced positive selection of TCR transgenic thymocytes in a coreceptor-independent manner. Immunity. 6:643-653.

35. Bachmann, M.F., Oxenius, A., Mak, T.W., and Zinkernagel, R.M. 1995. T cell development in CD8-/- mice: thymic positive selection is biased toward the helper phenotype. J. Immunol. 155:3727-3733.

36. Hernandez-Hoyos, G., Sohn, S.J., Rothenberg, E.V., and Alberola-Ila, J. 2000. Lck activity controls CD4/CD8 T cell lineage commitment. Immunity. 12:313-322.

37. Yasutomo, K., Doyle, C., Miele, L., and Germain, R.N. 2000. The duration of antigen receptor signalling determines CD4+ versus CD8+ T-cell lineage fate. Nature. 404:506-510.

38. Itano, A., and Robey, E. 2000. Highly efficient selection of CD4 and CD8 lineage thymocytes supports an instructive model of lineage commitment. Immunity. 12:383-389.

39. Kornfeld, S.J., et al. 1996. A novel mutation (Cys145 $\rightarrow$ Stop) in Bruton's tyrosine kinase is associated with newly diagnosed X-linked agammaglobulinemia in a 51-year-old male. Mol. Med. 2:619-623.

40. Shapiro, B.L., Newburger, P.E., Klempner, M.S., Dinauer, M.C. 1991. Chronic granulomatous disease presenting in a 69-year-old male. N. Engl. J. Med. 325:1786-1790.

41. Ozshahin, H., et al. 1997. Adenosin deaminase deficiency in adults. Blood. 89:2849-2855.

42. Arnaiz-Villena, A. et al. 1992. Brief report: primary immunodeficiency caused by mutations in the gene encoding the CD3- $\gamma$ subunit of the Tlymphocyte receptor. N. Engl. J. Med. 327:529-533.

43. Kornfeld, S.J., et al. 1997. Extreme variation in X-linked agammaglobulinemia phenotype in a three-generation family. J. Allergy Clin. Immunol. 100:702-706.

44. Sneller, M.C., et al. 1997. Clinical, immunological and genetic features of an autoimmune lymphoproliferative syndrome associated with abnormal lymphocyte apoptosis. Blood. 89:1341-1348.

45. Foster, C.B., et al. 1998. Host defense molecule polymorphisms influences the risk for immune-mediated complications in chronic granulomatous disease. J. Clin. Invest. 102:2146-2155. 